\title{
Biodiesel Synthesis through Methanolysis of Palm Olein Using Calcium Oxide Catalyst Derived from Staghorn Coral
}

\author{
Nabilah Atiqah Zul, ${ }^{1,2}$ Shangeetha Ganesan ${ }^{1}$ and M. Hazwan Hussin ${ }^{1,2^{*}}$ \\ ${ }^{1}$ School of Chemical Sciences, Universiti Sains Malaysia, \\ 11800 USM Pulau Pinang, Malaysia \\ ${ }^{2}$ Materials Technology Research Group (MaTReC), School of Chemical Sciences, \\ Universiti Sains Malaysia, 11800 USM Pulau Pinang, Malaysia \\ ${ }^{*}$ Corresponding author: mhh@usm.my
}

Published online: 25 April 2020

To cite this article: Zul, N. A., Ganesan, S. \& Hussin, M. H. (2020). Biodiesel synthesis through methanolysis of palm olein using calcium oxide catalyst derived from staghorn coral. J. Phys. Sci., 31(1), 37-55. https://doi.org/10.21315/jps2020.31.1.3

To link to this article: https://doi.org/10.21315/jps2020.31.1.3

\begin{abstract}
This study explored the synthesis of a heterogeneous catalyst derived from staghorn coral where it was utilised to convert palm olein into methyl esters through transesterification process. The prepared catalyst was characterised by various methods, namely Hammett indicator method, benzoic acid titration method, X-ray fluorescence (XRF) spectroscopy, Brunauer-Emmett-Teller (BET)- $N_{2}$ adsorption analysis, attenuated total reflectance-Fourier transform infrared (ATR-FTIR) spectroscopy, thermal gravimetric analysis (TGA), X-ray diffraction (XRD) analysis and scanning electron microscopy (SEM). Based on the results acquired from ATR-FTIR and XRD analyses, it was evident that staghorn coral was converted into calcium oxide (CaO) upon thermal activation at $900^{\circ} \mathrm{C}$. The impacts of catalyst loading, reaction time and methanol/oil molar ratio on biodiesel content were investigated to determine the optimum reaction conditions. The methyl esters content of $62.07 \%$ was achieved under optimised parameters comprising $6 \mathrm{wt} \%$ catalyst loading, reaction time of $4 \mathrm{~h}$ and methanol to oil molar ratio of $15: 1$. All in all, despite the low percentage of biodiesel production, staghorn coral has shown to be a potent catalyst and its catalytic ability could be improved to a whole new level through further modifications.
\end{abstract}

Keywords: Staghorn coral, catalyst, methanolysis, palm olein, biodiesel 


\section{INTRODUCTION}

Energy is one of the three most vital elements for human survival, ranked after food and water. ${ }^{1}$ Rapid advancements in economic development and population growth have resulted in a tremendous increase in energy demand. Since mankind has been relying heavily on fossil fuels as energy source, it is well known that its depletion is imminent and may impose negative impacts on the environment as well as human health. Thus, in order to replace the diminishing energy source while maintaining adequate energy supply, researchers have taken initiatives to implement biodiesel as an alternative energy source. Biodiesel is interpreted as fatty acid alkyl esters that are formed through the alcoholysis of animal fats/ vegetable oils in the presence of catalyst and alcohol. It is very well known as a good source of energy due to its excellent properties such as being renewable, biodegradable, environmentally friendly and generates less toxic emission. ${ }^{2}$

Generally, there are three classes of catalysts being used in biodiesel production which are enzymatic, homogeneous and heterogeneous catalysts. However, enzymatic catalysts are less popular due to their higher price, high sensitivity towards alcohol and low reaction rates. ${ }^{3,4}$ Sodium hydroxide $(\mathrm{NaOH})$ and potassium hydroxide $(\mathrm{KOH})$ are the two most frequently employed homogeneous catalysts in biodiesel formulation, attributed to numerous advantages such as the needs for moderate reaction conditions, higher conversion rates acquirable within a shorter time and being economically viable. ${ }^{5,6}$ However, their usage impose complications to separation and purification steps of biodiesel and glyceride. ${ }^{7,8}$ In addition, the purification process consumes and generates a massive amount of wastewater. ${ }^{4,9}$

Due to the aforementioned reasons, researchers have now shifted their focus to heterogeneous catalysts, whereby its utilisation benefits from various advantages over homogeneous catalysts. Heterogeneous catalysts are less corrosive, environmental friendly, offer better product separation, and require low water consumption. ${ }^{10}$ Some notable examples of heterogeneous catalysts are zeolite, $\mathrm{Mg} / \mathrm{Al}$ hydrotalcite and alkaline earth metal oxides. ${ }^{11-16}$ Out of all heterogeneous catalysts, calcium oxide $(\mathrm{CaO})$ has been praised as the most suitable catalyst in the transesterification process. Previously, many researchers have utilised waste materials such as golden snails (Pomacea sp.), eggshells, murex turnispina shell, quail eggshell and obtuse horn shell as sources of $\mathrm{CaO}$ catalysts. ${ }^{17-21}$ Additionally, the use of these waste materials as catalytic substances is one of the most viable approaches to lower the production cost. 
Hence, the present investigation was devoted to the utilisation of activated staghorn coral as heterogeneous catalyst to convert palm olein into biodiesel through transesterification process. Staghorn coral is a branching coral commonly exists in shallow water. It is one of the major groups of reef-corals responsible for about 122 valid species. ${ }^{22}$ Staghorn coral can be easily identified and differentiated from other corals as they possess distinctive branching that resembles male deer antlers. Remnants of dead staghorn corals can easily be found on coastlines of Malaysia, especially in the east coast areas, as they get washed ashore during high tides. To the best of our knowledge, utilisation of staghorn coral as base catalyst in palm olein transesterification has never been attempted. Therefore, the main objectives of this research are to characterise catalyst extracted from staghorn coral, to investigate the outcomes of varying experimental conditions on the percentage of biodiesel conversion, and to evaluate the potential of staghorn coral to be used as base catalyst in the alcoholysis of palm olein.

\section{EXPERIMENTAL}

\subsection{Materials}

Dead staghorn coral (Acropora cervicornis) fragments (Figure 1) were collected in 2016 from Beras Basah Island, Langkawi, Kedah, Malaysia. Palm olein was purchased from a local grocery store. Methanol and n-hexane were obtained from QRëC (Malaysia) while the internal standard (methyl heptadecanoate) was procured from Sigma-Aldrich (Switzerland).

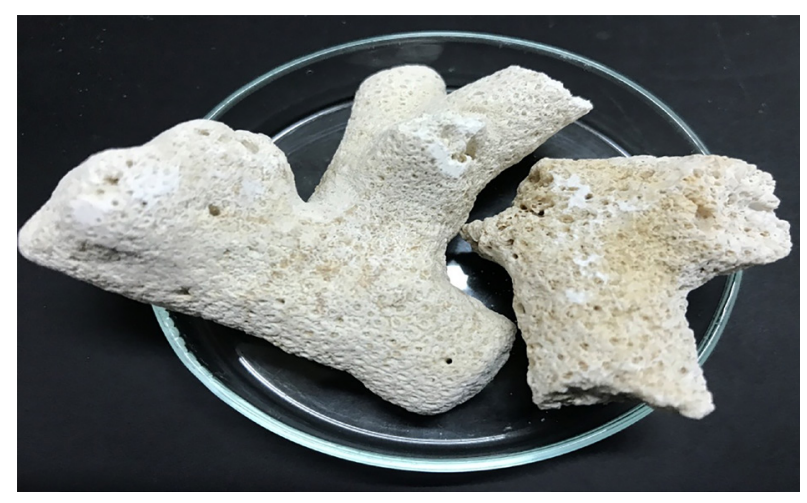

Figure 1: Dead staghorn coral fragment. 


\subsection{Catalyst Preparation}

The catalyst was prepared from dead staghorn coral fragments. The coral fragments were rinsed thoroughly under running tap water to remove all the attached impurities. They were then dried overnight in an oven at $105^{\circ} \mathrm{C}$. Next, these dried corals were ground repeatedly using mortar and pestle until they formed powder (hereinafter labelled as uncalcined staghorn coral, USC). The crushed and powdered corals were then sieved through a $250-\mathrm{mm}$ sieve before activating in a muffle furnace at $900^{\circ} \mathrm{C}$ for $4 \mathrm{~h}$ (hereinafter labelled as calcined staghorn coral, CSC).

\subsection{Characterisation of the Catalyst}

In the present work, several techniques were utilised to characterise USC and CSC samples. Basic strength and basicity of the samples were determined at ambient temperature using Hammett indicator and benzoic acid titration method respectively. X-ray fluorescence (XRF) study was conducted on a Rigaku RIX3000 XRF spectrometer by exploiting the pressed-pellet (at a pressure of $8.0 \mathrm{~Pa}$ ) technique to analyse the elemental compositions of catalysts. Brunauer-EmmettTeller (BET)-N2 adsorption analysis was executed on a Micromeritics ASAP 2000 analyser to find the surface area and pore structure of catalysts. Fourier transform infrared (FTIR) technique was performed using a Thermo-Nicolet IR 200 FTIR spectrometer coupled with an attenuated total reflectance (ATR) head to determine the functional groups that are present in the catalysts. Additionally, the catalysts were characterised using a Perkin Elmer TGA 7 analyser by adopting a temperature range of $30^{\circ} \mathrm{C}$ to $900^{\circ} \mathrm{C}$ at a heating rate of $10^{\circ} \mathrm{C} \mathrm{min}-1$. X-ray diffractometer (XRD, Siemens Diffractometer D5000) with $\mathrm{Cu} \mathrm{K \alpha}$ source was used to examine the crystalline phase of each catalyst. Data were collected over a $2 \theta$ of $25^{\circ}-125^{\circ}$ by applying a scanning speed of $1^{\circ} \mathrm{min}^{-1}$ and a step size of 0.05 . The surface morphologies of catalysts were identified by using a scanning electron microscope (SEM, Quanta FEI 650).

\subsection{Reaction Procedure}

A 50-ml round bottom flask together with a condenser, mechanical stirrer and thermometer were used during the transesterification reaction. Initially, approximately $5 \mathrm{~g}$ of oil was added into the round bottom flask with subsequent additions of different quantities of methanol and catalyst. Next, the experimental setup was immersed in a water bath with a constant temperature of $65^{\circ} \mathrm{C}$. The reaction mixture was then heated for $3 \mathrm{~h}$ to $6 \mathrm{~h}$ with continuous stirring. Following the completion of the reaction, the product was left to reach ambient room 
temperature, before biodiesel, glycerol and catalyst were further separated by centrifuging at $5000 \mathrm{rpm}$ for $10 \mathrm{~min}$. A measured quantity of n-hexane was used to isolate biodiesel. The purified biodiesel was then placed in a refrigerator until further use. The reaction was done in triplicate to achieve higher accuracy. The overall process of biodiesel production is presented in Figure 2. The sample was then subjected to characterisation and quantification utilising a gas chromatography with flame-ionisation detection (GC-FID, Agilent 7890A) accompanying a polar capillary column (Supelco-Wax, $30 \mathrm{~m} \times 0.25 \mathrm{~mm}$ i.d. $\times 0.25 \mu \mathrm{m}$ ), in accordance to the European procedure EN 14214. In this analysis, methyl heptadecanoate was used as the internal standard. The percentage conversion of palm olein into biodiesel was determined using the equation below:

$$
\text { Conversion }(\%)=\frac{\left(\Sigma^{\mathrm{A}}\right)-\mathrm{A}_{\text {ISTD }}}{\mathrm{A}_{\text {ISTD }}} \times \frac{\mathrm{C}_{\mathrm{ISTD}} \times \mathrm{V}_{\text {ISTD }}}{m} \times 100
$$

where $\Sigma^{\mathrm{A}}$ is the total peak area of FAME from C12:0 to C20:0, $\mathrm{A}_{\mathrm{ISTD}}$ is the peak area of methyl heptadecanoate, $\mathrm{C}_{\mathrm{ISTD}}$ is the concentration of methyl heptadecanoate $\left(\mathrm{mg} \mathrm{ml}^{-1}\right), \mathrm{V}_{\text {ISTD }}$ is the volume of methyl heptadecanoate $(\mathrm{ml})$, and $m$ is the mass of sample (mg).

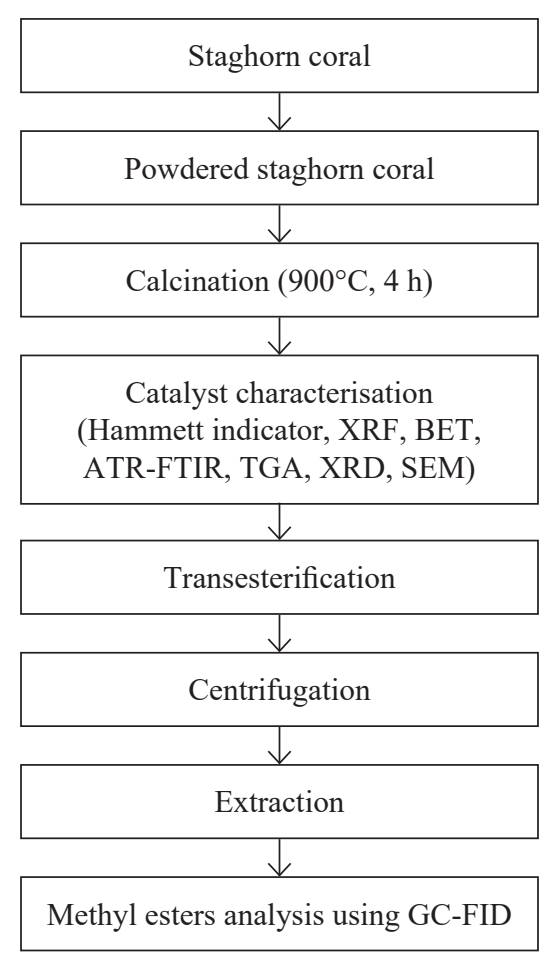

Figure 2: Flowchart of biodiesel production process. 


\section{RESULTS AND DISCUSSION}

\subsection{Catalyst Characterisation}

\subsubsection{Basic strength and basicity}

Basic strength and basicity values of USC and CSC samples are presented in Table 1 . The study showed that the colour of phenolphthalein $\left(H_{-}=8.2\right)$ solutions were changed from colourless to pink upon addition of both catalysts. However, USC sample did not alter the yellow colour of 2,4-dinitroaniline $\left(\mathrm{H}_{-}=15.0\right)$ to mauve, suggesting that it has a basic strength in the range of $8.2<\mathrm{H}_{-}<15.0$. On the other hand, CSC sample has altered the colour of 2,4-dinitroaniline $\left(\mathrm{H}_{-}=15.0\right)$ solution but not 4-nitroaniline $\left(\mathrm{H}_{-}=18.4\right)$ solution, indicating a basic strength of $15.0<\mathrm{H}_{-}<18.4$. Thus, it is considered as a sturdy base catalyst which is most likely caused by the existence of strong basic sites on its surface. ${ }^{23,24}$ As a comparison, the results obtained were found to be higher than those of CaO-derived palm kernel shell reported by Bazargan et al. ${ }^{25}$ In terms of basicity, USC sample possessed very low basicity value (i.e., $0.01 \mathrm{mmol} \mathrm{g}^{-1}$ ). Upon calcination at $900^{\circ} \mathrm{C}$, the basicity increased up to $0.14 \mathrm{mmol} \mathrm{g}^{-1}$. It is evident that calcination provokes the formation of basic sites, acquiring a higher basicity than that obtained by Udomman et al., where the activated eggshell, cockle shell and crab shell (basic strength of $9.3<\mathrm{H}_{-}<15.0$ ) showed basicity of $0.040 \mathrm{mmol}$ $\mathrm{g}^{-1}, 0.023 \mathrm{mmol} \mathrm{g}^{-1}$ and $0.016 \mathrm{mmol} \mathrm{g}^{-1}$, respectively. ${ }^{26}$

Table 1: Basic strength and basicity of the prepared catalysts.

\begin{tabular}{lcc}
\hline & USC & CSC \\
\hline Basic strength & $8.2<\mathrm{H}_{-}<15.0$ & $15.0<\mathrm{H}_{-}<18.4$ \\
Basicity $\left(\mathrm{mmol} \mathrm{g}^{-1}\right)$ & 0.01 & 0.14 \\
\hline
\end{tabular}

\subsubsection{XRF analysis}

Elemental compositions of catalysts are depicted in Table 2. XRF data demonstrated that the major element found in both samples is calcium, further proving that staghorn coral is mainly composed of calcium carbonate. Upon calcination, the percentage of calcium increased slightly from $92.68 \%$ to $93.86 \%$ which is probably associated with the increment in basic active sites in the form of $\mathrm{O}^{2-}$. This result is in accordance with the data reported by Agrawal et al., where Pila globosa shell mostly contained $\mathrm{CaO}(79.80 \%) .{ }^{27}$ While other elements such as $\mathrm{Si}, \mathrm{Sr}, \mathrm{Ti}$ and $\mathrm{Al}$, etc., were found in trace amounts and considered as impurities. Therefore, staghorn coral could be a potent catalyst in biodiesel production due to its high calcium content. 
Table 2: Elemental compositions of staghorn coral-derived catalysts.

\begin{tabular}{lcc}
\hline Oxide & USC (\%) & CSC (\%) \\
\hline $\mathrm{CaO}$ & 92.68 & 93.86 \\
$\mathrm{SiO}_{2}$ & 2.13 & 2.11 \\
$\mathrm{SrO}$ & 1.83 & 1.57 \\
Others & 2.40 & 1.66 \\
\hline Notes: ${ }^{*} \mathrm{TiO}_{2}, \mathrm{Al}_{2} \mathrm{O}_{3}, \mathrm{Fe}_{2} \mathrm{O}_{3}, \mathrm{MnO}, \mathrm{MgO}, \mathrm{Na}_{2} \mathrm{O}, \mathrm{K}_{2} \mathrm{O}, \mathrm{P}_{2} \mathrm{O}_{5}$
\end{tabular}

\subsubsection{BET- $\mathrm{N}_{2}$ adsorption analysis}

Comparison of physical properties of USC and CSC samples is provided in Table 3. According to the results obtained, CSC sample has a higher surface area $\left(5.2439 \mathrm{~m}^{2} \mathrm{~g}^{-1}\right)$ and a bigger pore volume $\left(0.009320 \mathrm{~cm}^{3} \mathrm{~g}^{-1}\right)$ than USC sample $\left(1.3033 \mathrm{~m}^{2} \mathrm{~g}^{-1}\right.$ and $0.004307 \mathrm{~cm}^{3} \mathrm{~g}^{-1}$, respectively), revealing that the calcination process has resulted in crystal growth of $\mathrm{CaO}$ which consequently reduced the catalyst size. ${ }^{28}$ As the size of catalyst decreases, the active surface area of the catalyst increases. Thus, the smaller the particle, the lesser the amount of catalyst is needed during the reaction, leading to a better catalytic activity. In other words, a catalyst with a large surface area is postulated to have higher efficiency. ${ }^{29}$ Besides, the increase in surface area of CSC sample is probably due to the presence of pores between the particles, as a result of the calcination process which was further validated through SEM study, shown in Figure 7(b). ${ }^{30}$

Table 3: The physical properties of staghorn coral-derived catalyst.

\begin{tabular}{lcc}
\hline Physical properties & USC & CSC \\
\hline Surface area $\left(\mathrm{m}^{2} \mathrm{~g}^{-1}\right)$ & 1.3033 & 5.2439 \\
Pore volume $\left(\mathrm{cm}^{3} \mathrm{~g}^{-1}\right)$ & 0.004307 & 0.009320 \\
Pore size $\left(\mathrm{A}^{\circ}\right)$ & 132.1982 & 71.0914 \\
\hline
\end{tabular}

In comparison to USC sample, CSC sample demonstrated a slightly higher pore volume, probably caused by the porosity development in the sample. ${ }^{31}$ Figure 3 depicts nitrogen adsorption-desorption isotherms of USC and CSC samples. Both catalysts showed Type IV isotherm which is correlated to mesoporous solids. ${ }^{32}$ Besides, a hysteresis loop existed between the adsorption and desorption curves, further clarifying the presence of mesoporosity. ${ }^{33}$ In addition, both samples demonstrated type $\mathrm{H} 3$ hysteresis which is reminiscent of open slit-shaped capillaries. 
(a)

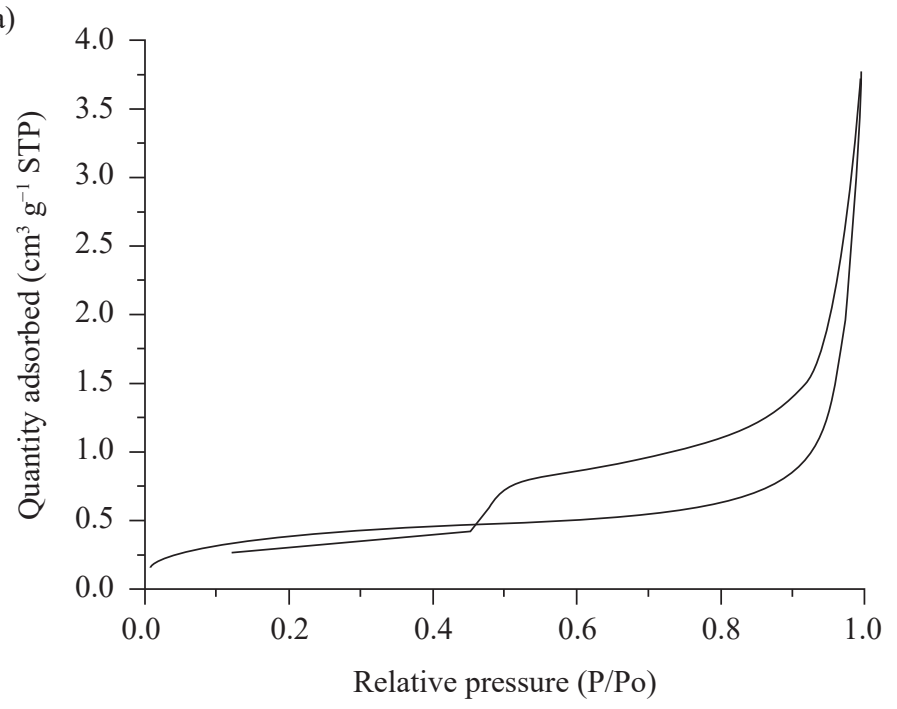

(b)

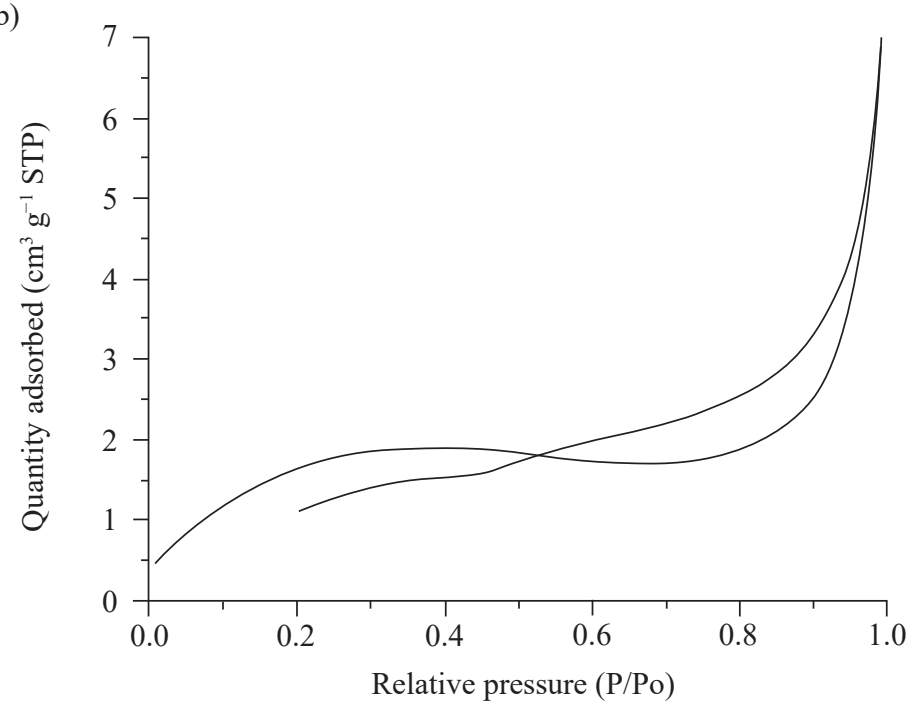

Figure 3: Nitrogen adsorption-desorption isotherms of (a) USC, and (b) CSC samples.

\subsubsection{ATR-FTIR analysis}

The IR spectra of USC and CSC samples are presented in Figure 4. Most of the peaks related to USC sample are attributed to carboxyl species, suggesting that $\mathrm{CaCO}_{3}$ is the major compound. It also shows that intensities of IR peaks decreased after the catalyst was subjected to thermal activation process $\left(900^{\circ} \mathrm{C}\right.$, $4 \mathrm{~h}$ ). This might imply that the loss of carbonate ion group attached to the catalyst 
surface. ${ }^{28}$ The presence of $\mathrm{CaO}$ in $\mathrm{CSC}$ sample was indicated by the vibrational band positioned at $874 \mathrm{~cm}^{-1}$, which is comparable with the study accomplished by Ruiz et al..$^{34}$ Meanwhile, the presence of carbonate species gave rise to the bands recorded at $1181 \mathrm{~cm}^{-1}$ and $1420 \mathrm{~cm}^{-1}$. An absorption peak detected at $3640 \mathrm{~cm}^{-1}$ verified the presence of hydroxyl group attached to calcium atoms where Margaretha et al. outlined a similar interpretation. ${ }^{17,35}$ The presence of carbonyl and hydroxyl peaks is correlated to the exposure of activated coral to the atmosphere during the analysis, signifying the ability of calcined coral to absorb $\mathrm{CO}_{2}$ and $\mathrm{H}_{2} \mathrm{O}$ in a short period of time.

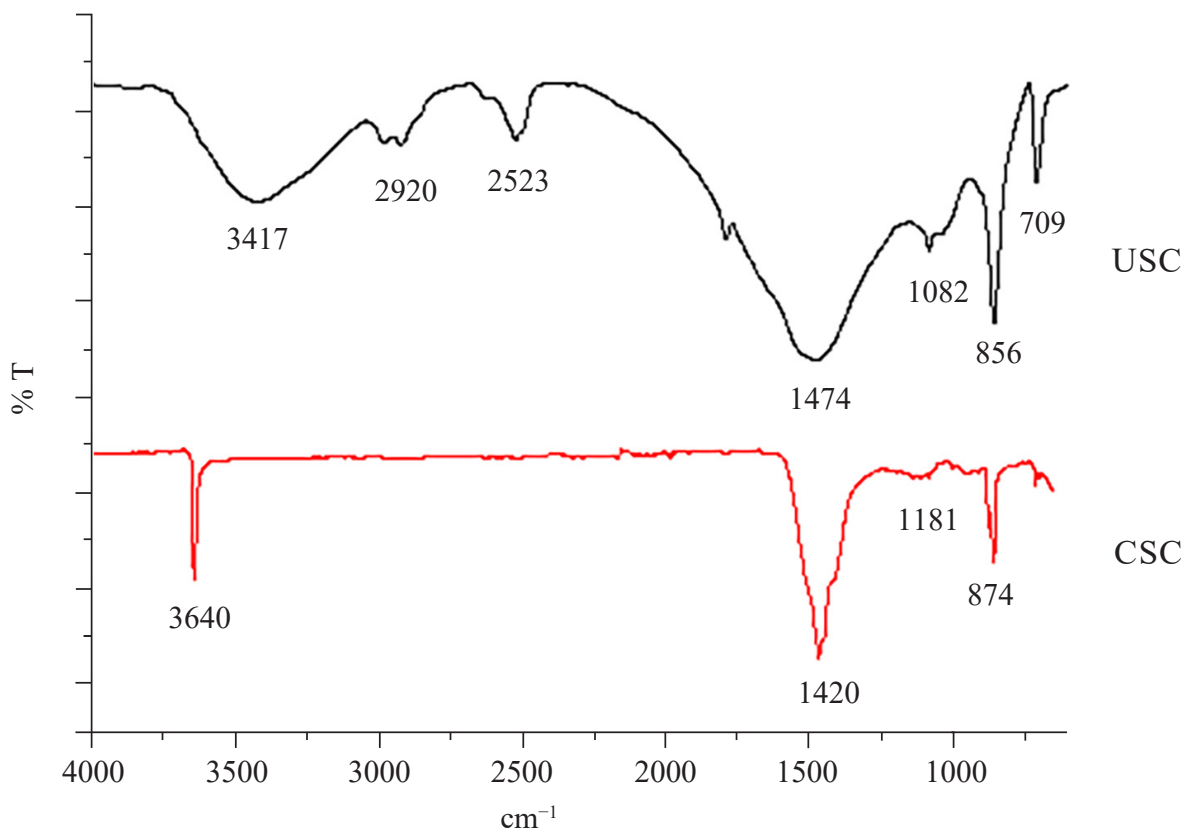

Figure 4: IR spectra of USC and CSC samples.

\subsubsection{TGA}

Thermal decomposition of USC sample was studied by conducting TGA in the temperature range of $30^{\circ} \mathrm{C}$ to $900^{\circ} \mathrm{C}$ (Figure 5). The thermogram shows two decomposition stages where the first stage depicted a minor weight loss of $1.2 \%$ initiated at $280^{\circ} \mathrm{C}$, associated with the removal of organic matter. Meanwhile, the second decomposition stage was observed in the temperature range of $550^{\circ} \mathrm{C}-760^{\circ} \mathrm{C}$ accompanying a major decomposition of $41.8 \%$, suggesting complete degradation of $\mathrm{CaCO}_{3}$ into $\mathrm{CaO}$. The sample weight remained almost constant after $800^{\circ} \mathrm{C}$, evidencing that the suitable calcination temperature could be above $800^{\circ} \mathrm{C}$. 


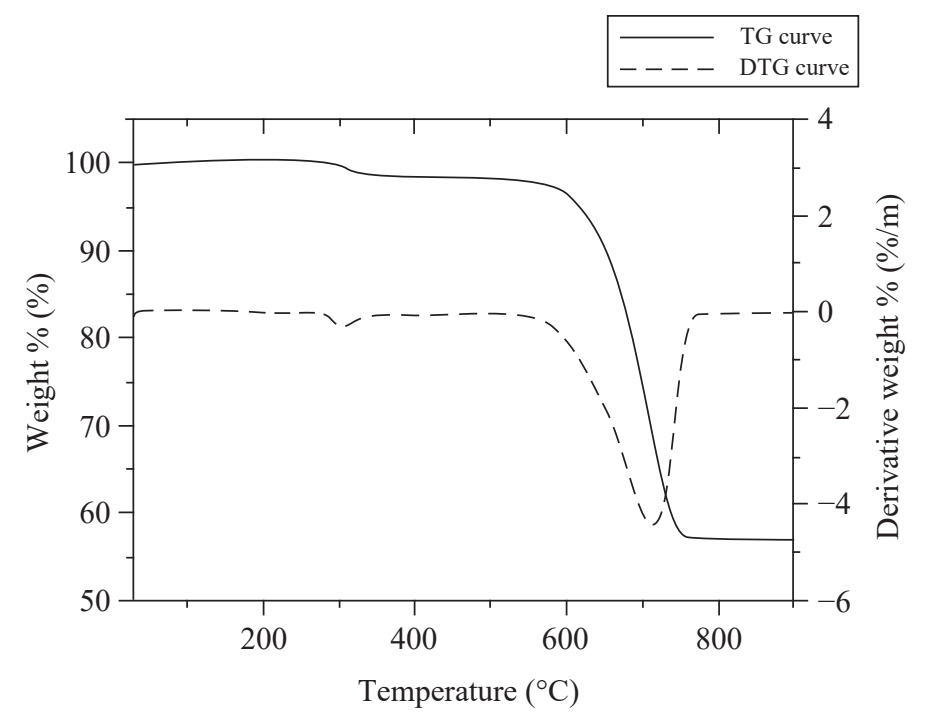

Figure 5: TG/DTG thermogram of USC sample.

\subsubsection{XRD analysis}

The XRD profiles of USC and CSC samples are presented in Figure 6. Diffraction patterns of USC sample demonstrated that the main peaks at $2 \theta=26.144^{\circ}, 33.075^{\circ}$, $35.788^{\circ}, 38.281^{\circ}, 41.145^{\circ}, 45.746^{\circ}, 48.296^{\circ}$ and $52.638^{\circ}$ were associated with $\mathrm{CaCO}_{3}$. Moreover, the existence of $\mathrm{Ca}(\mathrm{OH})_{2}$ was evident by the peaks positioned at $2 \theta=50.178^{\circ}, 63.125^{\circ}, 79.396^{\circ}$ and $82.141^{\circ}$. However, most of the peaks disappeared after subjecting to calcination process $\left(900^{\circ} \mathrm{C}, 4 \mathrm{~h}\right)$. The sharp peaks of CSC sample appeared at $2 \theta=32.214^{\circ}, 37.702^{\circ}, 53.873^{\circ}, 64.135^{\circ}, 67.328^{\circ}$, $88.520^{\circ}, 91.452^{\circ}$ and $103.335^{\circ}$ were indication of the single crystalline phase of $\mathrm{CaO}$. The peaks representing $\mathrm{Ca}(\mathrm{OH})_{2}$ were spotted at $2 \theta=34.209^{\circ}, 50.863^{\circ}$ and $79.755^{\circ}$ which were virtually identical with those reported by Boro et al. and Sharma et al..$^{31,36}$ 


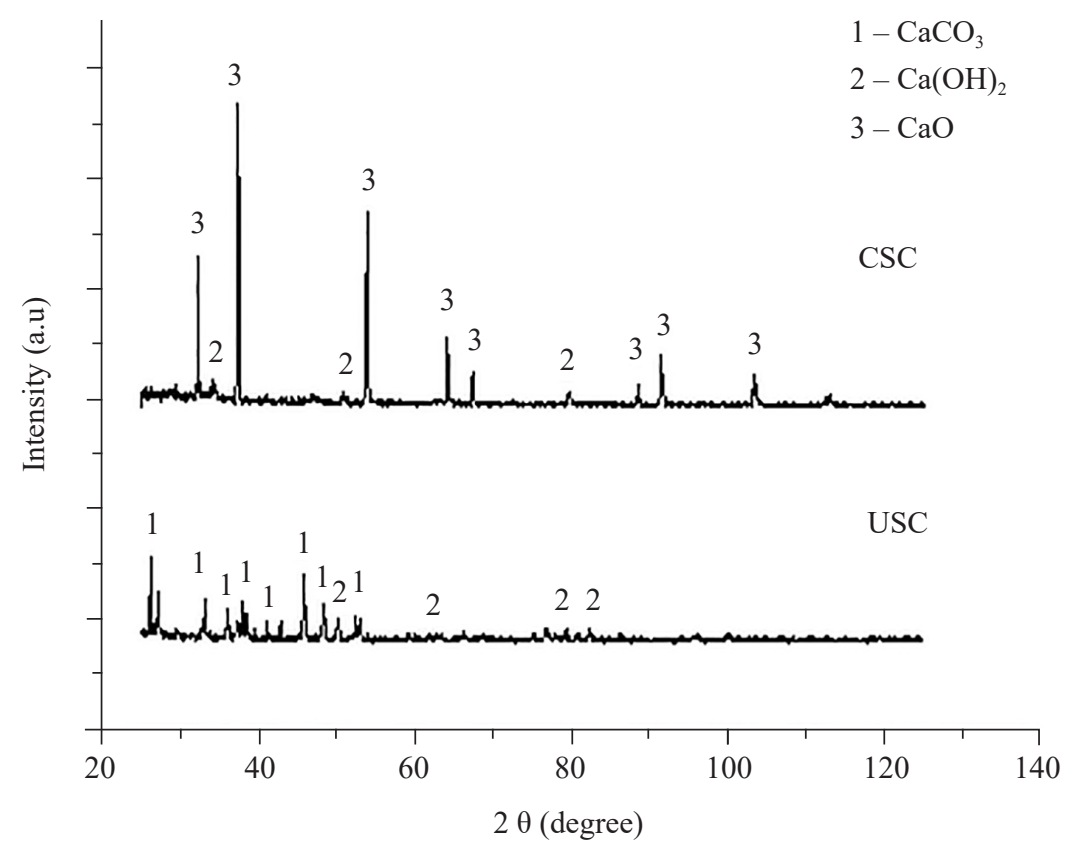

Figure 6: XRD patterns of USC and CSC catalysts.

\subsubsection{SEM analysis}

The morphology of the catalysts was investigated by using SEM at a magnification power of 2500X. As depicted in Figure 7, there are clear differences between the micrographs obtained before and after the calcination process. In the case of USC sample, the catalyst possesses irregular and uneven surface, shown in Figure 7(a). Besides, this sample also comprises various shapes and sizes of particles and pores, which clearly has fewer pores than CSC sample. With regards to Figure 7(b), CSC sample showed an image with more contrasting results against USC sample, suggesting that calcination at $900^{\circ} \mathrm{C}$ has resulted in a wavelike surface with various sizes of particles. This finding is comparable to the data acquired by Mamat and Yacob where even calcined eggshells possessed a wavelike surface. ${ }^{37}$ In addition, CSC sample is obviously more porous than USC sample. According to Tan et al., the change in the structure of the catalyst is most likely due to the compositional change such as the decomposition of $\mathrm{CaCO}_{3}$ into $\mathrm{CaO}$, which reduces its particle size. ${ }^{38}$ 

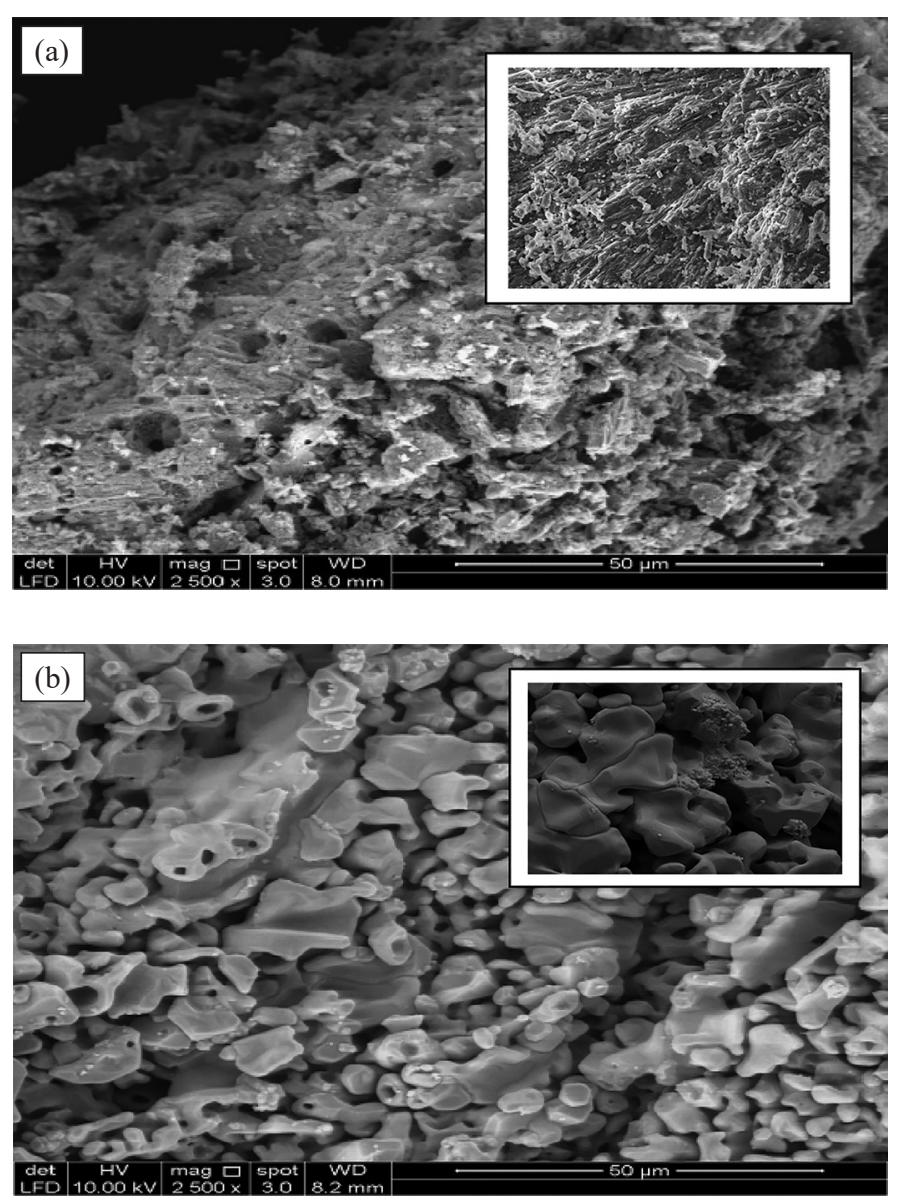

Figure 7: SEM images of (a) USC, and (b) CSC samples at 2500X magnifications.

\subsection{Optimisation of Transesterification over CSC Catalyst}

\subsubsection{Effects of catalyst loading}

Catalyst loading is a vital criterion in biodiesel production. Figure 8 illustrates the outcomes of catalyst loading on the biodiesel content. It was observed that the reaction rate increased drastically when the catalyst loading was changed from $5 \mathrm{wt} \%$ to $6 \mathrm{wt} \%$. This phenomenon is probably caused by a rise in the accumulation of protons at oil-methanol interface which in turn enhanced the reaction where the percentage conversion of biodiesel decreased from $62.07 \%$ to $46.67 \%$ with the catalyst loading of $7 \mathrm{wt} \%{ }^{39}$ This could be related to the catalytic reduction which resulted in the formation of a more viscous reaction mixture that 
made it more difficult to be stirred. ${ }^{40,41}$ Therefore, an effective mixing is required to enhance the reaction rate. As a comparison, Nakatani et al. used $\mathrm{CaO}$ derived from an oyster shell as a catalyst in the transesterification of soybean oil whereby the reaction reached completion upon the use of $25 \mathrm{wt} \%$ catalyst, which is much higher than that of catalyst amount utilised in this study..$^{42}$ Besides, Huang et al. reported the application of commercial $\mathrm{CaO}$ and activated commercial $\mathrm{CaO}$ as catalysts which had yielded about $4.0 \%$ and $87.3 \%$ of biodiesel content, respectively. ${ }^{43}$ Apart from gaining a higher conversion, commercial $\mathrm{CaO}$ does not provide any economic and environmental benefits that staghorn coral does.

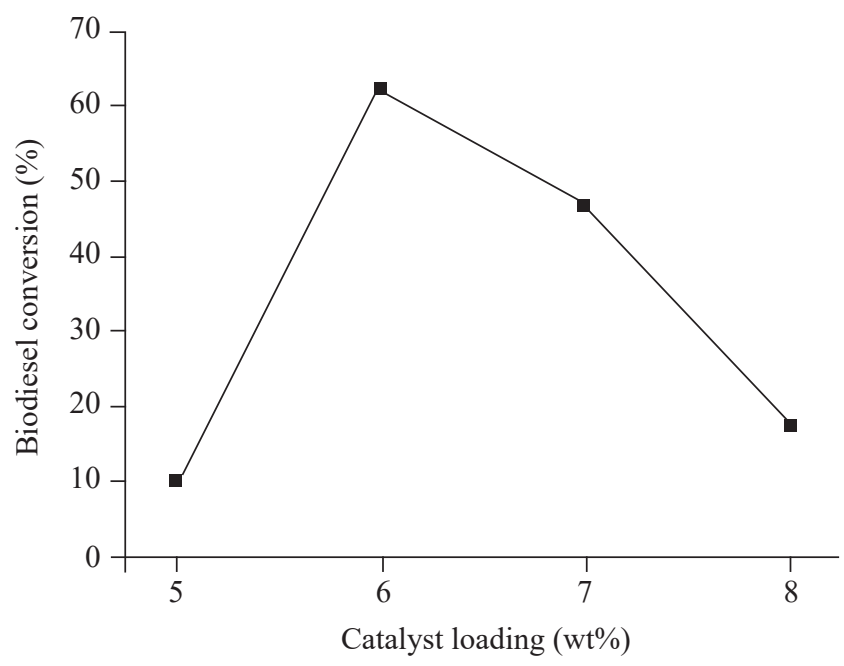

Figure 8: Impact of catalyst loading on biodiesel conversion under reaction conditions of $\mathrm{MeOH} /$ oil ratio of 15:1 and $4 \mathrm{~h}$ reaction time.

\subsubsection{Effects of reaction time}

As illustrated in Figure 9, a shift in the reaction time from $3 \mathrm{~h}$ to $6 \mathrm{~h}$ had profound effects on the biodiesel conversion. At the third hour, a very low methyl esters content $(5.58 \%)$ was recorded whereas when the experimental time was prolonged to $4 \mathrm{~h}$, the reaction yielded the highest biodiesel conversion $(62.07 \%)$, attributed to the extended contact time between reactants. ${ }^{44}$ However, there was a declining trend in the catalytic activity after $5 \mathrm{~h}$ of reaction time since the longer the reaction time, the higher the amount of products that would be absorbed by the catalyst, thus yielding more by-products. ${ }^{45,46}$ More importantly, this study endured a shorter reaction time for the reaction to be completed than that reported by Nakatani et al. The authors reported less than $80 \%$ of biodiesel yield only after $5 \mathrm{~h}$ of reaction. ${ }^{42}$ 


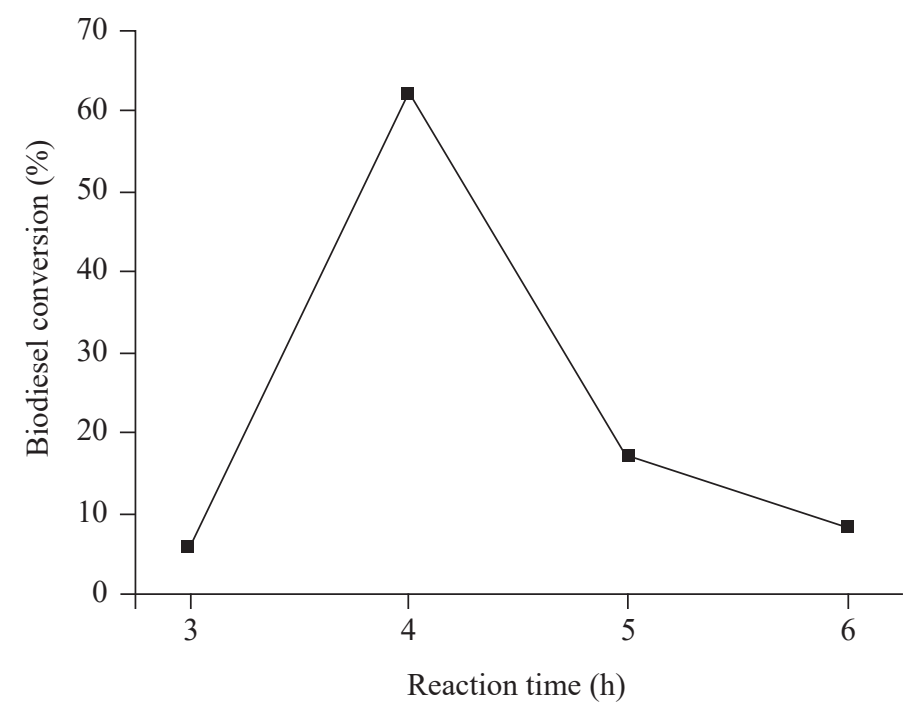

Figure 9: Impact of reaction time on biodiesel conversion under reaction conditions of $6 \mathrm{wt} \%$ catalyst loading and $\mathrm{MeOH} /$ oil ratio of $15: 1$.

\subsubsection{Effects of methanol to oil molar ratio}

Besides catalyst loading and reaction time, methanol to oil molar ratio is one of the most crucial parameters that can contribute prompt impacts on the reaction rate. In the present work, the reaction rate increased as the methanol to oil molar ratio changed from 12:1 to 15:1 (Figure 10), which is due to an increase in the interaction between methanol and oil. ${ }^{47}$ However, the biodiesel content has dropped to $54.36 \%$ when methanol/oil molar ratio of 18:1 was used, pertaining to the fact that excess methanol might enhances glycerol solubility which in turn hinders the interaction of methanol with the catalyst and oil. ${ }^{48}$ Thus, $15: 1$ has been chosen as the optimum ratio of methanol to oil. According to the observation-based study attempted by Abdel-Rahman et al., the use of commercial $\mathrm{CaO}$ as catalyst produced more than $90 \%$ of biodiesel yield under methanol to oil ratio of $10: 1 .{ }^{49}$ Although their reported yield is higher than the yield achieved in the current work, staghorn coral could offer better advantage in terms of economical prospect. 


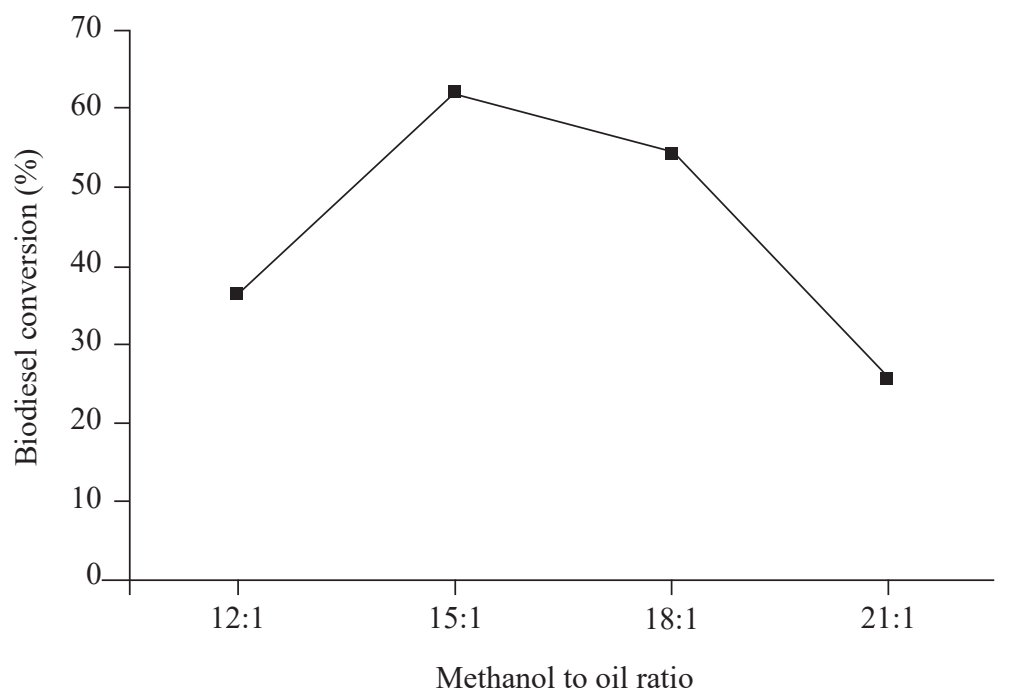

Figure 10: Impact of methanol to oil ratio on biodiesel conversion under reaction conditions of $6 \mathrm{wt} \%$ catalyst loading and $4 \mathrm{~h}$ of reaction time.

\section{CONCLUSION}

In this paper, we presented a low cost and green catalyst derived from dead staghorn coral fragments via thermal activation process at $900^{\circ} \mathrm{C}$ for $4 \mathrm{~h}$. This catalyst was composed of more than $90 \% \mathrm{CaO}$ with a surface area of $5.2439 \mathrm{~m}^{2} \mathrm{~g}^{-1}$. It was successfully employed in biodiesel production through transesterification. The overall results indicated that a biodiesel conversion of $62.07 \%$ recorded under the reaction conditions of $6 \mathrm{wt} \%$ catalyst, $4 \mathrm{~h}$ of reaction and 15:1 molar ratio of methanol/oil with continuous stirring at $500 \mathrm{rpm}$. In conclusion, the staghorn coral has demonstrated a promising potential to be commercialised as source for biodiesel production, with its catalytic activity that can be further improved with minimal modifications.

\section{ACKNOWLEDGEMENTS}

The authors acknowledge Universiti Sains Malaysia (USM) for the financial support through USM grant number 304/PKIMIA/6316041. 


\section{REFERENCES}

1. Zou, C. et al. (2016). Energy revolution: From a fossil energy era to a new energy era. Nat. Gas Ind. B, 3, 1-11. https://doi.org/10.1016/j.ngib.2016.02.001

2. Mishran, V. K. \& Goswami, R. (2018). A review of production, properties and advantages of biodiesel. Biofuels, 9, 273-289. https://doi.org/10.1080/17597269 .2017.1336350

3. Bajaj, A. et al. (2010). Biodiesel production through lipase catalyzed transesterification: An overview. J. Mol. Catal. B Enz., 62, 9-14. https://doi. org/10.1016/j.molcatb.2009.09.018

4. Leung, D. Y. C., Wu, X. \& Leung, M. K. H. (2010). A review on biodiesel production using catalyzed transesterification. Appl. Energy, 87, 1083-1095. https://doi.org/10.1016/j.apenergy.2009.10.006

5. Lam, M. K., Lee, K. T. \& Mohamed, A. R. (2010). Homogenous, heterogenous and enzymatic catalysis for transesterification of high free fatty acid oil (waste cooking oil) to biodiesel: A review. Biotechnol. Adv., 28, 500-518. https://doi. org/10.1016/j.biotechadv.2010.03.002

6. Atadashi, I. M. et al. (2013). The effects of catalysts in biodiesel production: A review. J. Ind. Eng. Chem., 19, 14-26. https://doi.org/10.1016/j.jiec.2012.07.009

7. Zhang, Y. et al. (2003). Biodiesel production from waste cooking oil: 2. Economic assessment and sensitivity analysis. Bioresour. Technol., 90, 229-240. https://doi. org/10.1016/S0960-8524(03)00150-0

8. Zhang, Y. et al. (2003). Biodiesel production from waste cooking oil: 1. Process design and technological assessment. Bioresour. Technol., 89, 1-16. https://doi. org/10.1016/S0960-8524(03)00040-3

9. Srivastava, A. \& Prasad, R. (2000). Triglycerides-based diesel fuels. Renew. Sust. Energy Rev., 4, 111-133. https://doi.org/10.1016/S1364-0321(99)00013-1

10. Othman, M. et al. (2009). Solid heterogeneous catalysts for transesterification of triglycerides with methanol: A review. Appl. Catal. A, 363, 1-10. https://doi. org/10.1016/j.apcata.2009.05.021

11. Brito, A., Borges, M. E. \& Otero, N. (2007). Zeolite Y as a heterogeneous catalyst in biodiesel fuel production from used vegetable oil. Energy Fuels, 21, 3280-3283. https://doi.org/10.1021/ef700455r

12. Carrero, A. et al. (2011). Hierarchical zeolites as catalysts for biodiesel production from Nannochloropsis microalga oil. Catal. Today, 167, 148-153. https://doi.org/ 10.1016/j.cattod.2010.11.058

13. Gomes, J. F. P. et a. (2011). Study on the use of MgAl hydrotalcites as solid heterogeneous catalysts for biodiesel production. Energy, 36, 6770-6778. https://doi.org/10.1016/j.energy.2011.10.024

14. Serio, M. D. et al. (2012). Mg/Al hydrotalcite catalyst for biodiesel production in continuous packed bed reactors. Catal. Today, 195, 54-58. https://doi. org/10.1016/j.cattod.2012.01.013 
15. Babak, S., Iman, H. \& Abdullah, A. Z. (2013). Alkaline earth metal oxide catalysts for biodiesel production from palm oil: Elucidation of process behaviors and modeling using response surface methodology. Iran. J. Chem. Chem. Eng., 32, 113-126.

16. Buasri, A. et al. (2013). Application of eggshell waste as a heterogeneous catalyst for biodiesel production. Sustain. Energy, 1, 7-13. https://doi.org/10.12691/rse-12-1

17. Margaretha, Y. Y. et al. (2012). Calcium oxide from Pomacea sp. shell as a catalyst for biodiesel production. Int. Energy Environ. Eng., 3, 1-9. https://doi. org/10.1186/2251-6832-3-33.

18. Omotoso, M. A. \& Iro-Idoro, E. U. (2015). Efficiency of quail eggshell as heterogeneous catalyst for production of biodiesel from Momordica charantia linn seed and rice bran. Am. J. Eng. Technol. Res., 15, 55-79.

19. Ekeoma, M. O. et al. (2017). Murex turnispina shell as catalyst for bio-diesel production. Int. Res. J. Pure Appl. Chem., 14, 1-13. https://doi.org/10.9734/ IRJPAC/2017/32578.

20. Correia, L. M. et al. (2017). Relevance of the physicochemical properties of calcined quail eggshell $(\mathrm{CaO})$ as a catalyst for biodiesel production. J. Chem., Article ID 5679512, 1-12. https://doi.org/10.1155/2017/5679512

21. Lee, S. L. et al. (2015). Transesterification of palm oil to biodiesel by using waste obtuse horn shell-derived CaO catalyst. Energy Convers. Manage., 93, 282-288. https://doi.org/10.1016/j.enconman.2014.12.067

22. Wallace, C., Done, B. J. \& Muir, P. R. (2012). Revision and catalogue of worldwide staghorn corals Acropora and Isopora (Scleractinia: Acroporidae) in the museum of tropical Queensland. Mem. Queensl. Mus., 57, 1-255.

23. Boey, P-L. et al. (2011). Crab and cockle shells as catalysts for the preparation of methyl esters from low free fatty acid chicken fat. J. Am. Oil Chem. Soc., 88, 283-238. https://doi.org/10.1007/s11746-010-1660-4

24. Kumar, D. \& Ali, A. (2010). Nanocrystalline lithium ion impregnated calcium oxide as heterogeneous catalyst for transesterification of high moisture containing cotton seed oil. Energy Fuels, 24, 2091-2097. https://doi.org/10.1021/ef901318s

25. Bazargan, A. et al. (2015). A calcium oxide-based catalyst derived from palm kernel shell gasification residues for biodiesel production. Fuel, 150, 519-525. https://doi.org/10.1016/j.fuel.2015.02.046

26. Udomman, T. et al. (2015). Kinetic study of biodiesel synthesis from palm oil by using low-cost calcium oxide catalyst. Eng. Trans., 18, 70-75.

27. Agrawal, S., Singh, B. \& Sharma, Y. C. (2012). Exoskeleton of a mollusk (Pila globosa) as a heterogeneous catalyst for synthesis of biodiesel using used frying oil. Ind. Eng. Chem Res., 51, 11875-11880. https://doi.org/10.1021/ ie202404r

28. Birla, A. et al. (2012). Kinetics studies of synthesis of biodiesel from waste frying oil using a heterogeneous catalyst derived from snail shell. Bioresour. Technol., 106, 95-100. httsp://doi.org/10.1016/j.biortech.2011.11.065 
29. Kumar, D. \& Ali, A. (2012). Nanocrystalline K-CaO for the transesterification of a variety of feedstocks: Structure, kinetics and catalytic properties. Biomass Bioenergy, 46, 459-468. https://doi.org/10.1016/j.biombioe.2012.06.040

30. Correia, L. M. et al. (2017). Relevance of the physicochemical properties of calcined quail eggshell $(\mathrm{CaO})$ as a catalyst for biodiesel production. J. Chem., Article ID 5679512, 1-12. https://doi.org/10.1155/2017/5679512

31. Boro, J., Thakur, A. J. \& Deka, D. (2011). Solid oxide derived from waste shells Turbonilla striatula as a renewable catalyst for biodiesel production. Fuel Process. Technol., 92, 2061-2067. https://doi.org/10.1016/j.fuproc.2011.06.008

32. Panda, A., Mishra, B. \& Singh, R. (2010). Effect of sulphuric acid treatment on the physicochemical characteristics of kaolin clay. Coll. Surf. A Physicochem. Eng. Asp., 363, 98-104. https://doi.org/10.1016/j.colsurfa.2010.04.022

33. Zielinski, J. M. \& Kettle, L. (2013). Physical characterization: surface area and porosity. London: Intertek.

34. Ruiz, M. G. et al. (2009). Characterization of calcium carbonate, calcium oxide, and calcium hydroxide as starting point to the improvement of lime for their use in construction. J. Mater. Civ. Eng., 21, 694-698.

35. Garcia, J. L. T. et al. (2008). Spectroscopic, structural and textural properties of $\mathrm{CaO}$ and $\mathrm{CaO}-\mathrm{SiO}_{2}$ materials synthesized by sol-gel with different acid catalysts. J. Non. Cryst. Solids, 354, 729-732. https://doi.org/10.1016/j. jnoncrysol.2007.07.074

36. Sharma, Y. C., Singh, B. \& Korstad, J. (2010). Application of an efficient nonconventional heterogeneous catalyst for biodiesel synthesis from Pongamia pinnata oil. Energy Fuels, 24, 3223-3231. https://doi.org/10.1021/ef901514a

37. Mamat, F. M. \& Yacob, A. R. (2015). Kinetic study of biodiesel using egg shell for base transesterification reaction. Chemistry Undergraduate Final Year Project Symposium, Faculty of Science, Universiti Teknologi Malaysia. Retrieved 15 March 2018 from http://eprints.utm.my/id/eprint/62086/1/ZainabRamli2015 ModifiedDesilicatedNaturalZeoliteas CatalystinKnoevenagelReaction. pdf\#page $=75$.

38. Tan, Y. H. et al. (2015). Waste ostrich- and chicken-eggshells as heterogeneous base catalyst for biodiesel production from used cooking oil: Catalyst characterization and biodiesel yield performance. Appl. Energy, 160, 58-70. https://doi. org/10.1016/j.apenergy.2015.09.023

39. Wu, H. et al. (2013). Transesterification of soybean oil to biodiesel using zeolite supported $\mathrm{CaO}$ as strong base catalysts. Fuel Process. Technol., 109, 13-18. https://doi.org/10.1016/j.fuproc.2012.09.032

40. Liu, H. et al. (2016). Mixed and ground KBr-impregnated calcined snail shell and kaolin as solid base catalysts for biodiesel production. Renew. Energy, 93, 648657. https://doi.org/10.1016/j.renene.2016.03.017

41. Kataria, J., Mohapatra, S. K. \& Kundu, K. (2017). Biodiesel production from frying oil using zinc-doped calcium oxide as heterogeneous catalysts. Energy Sour. A, 39, 861-866. https://doi.org/10.1080/15567036.2016.1270376 
42. Nakatani, N. et al. (2009). Transesterification of soybean oil using combusted oyster shell waste as a catalyst. Bioresour. Technol., 100, 1510-1513. https://doi. org/10.1016/j.biortech.2008.09.007

43. Huang, W. et al. (2013). Activation of commercial $\mathrm{CaO}$ for biodiesel production from rapeseed oil using a novel deep eutectic solvent. Ind. Eng. Chem. Res., 52, 11943-11947. https://doi.org/10.1021/ie401292w

44. Suryaputra, W. et al. (2013). Waste capiz (Amusium cristatum) shell as a new heterogeneous catalyst for biodiesel production. Renew. Energy, 50, 795-799. https://doi.org/10.1016/j.renene.2012.08.060

45. Taufiq-Yap, Y. H. et al. (2011). Calcium-based mixed oxide catalysts for methanolysis of Jatropha curcas oil to biodiesel. Biomass Bioenergy, 35, 827-834. https://doi.org/10.1016/j.biombioe.2010.11.011

46. Zhang, J. \& Meng, Q. (2014). Preparation of $\mathrm{KOH} / \mathrm{CaO} / \mathrm{C}$ supported biodiesel catalyst and application process. World J. Eng. Technol., 2, 184-191. https://doi. org/10.4236/wjet.2014.23020

47. Sirisomboonchai, S. et al. (2015). Biodiesel production from waste cooking oil using calcined scallop shell as catalyst. Energ Conver. Manage., 95, 242-247. https://doi.org/10.1016/j.enconman.2015.02.044

48. Lim, B. P., Maniam, G. P. \& Hamid, S. A. (2009). Biodiesel from adsorbed waste oil on spent bleaching clay using $\mathrm{CaO}$ as a heterogeneous catalyst. Eur. J. Sci. Res., 33, 347-357.

49. Abdel-Rahman, Z., Wiheeb, A. \& Jumaa, M. (2017). Commercial CaO catalyzed biodiesel production process. Al-Nahrain J. Eng. Sci., 20, 846-852. 